\title{
Moral agents in medical research and practice
}

\author{
Wim Dekkers · Bert Gordijn
}

Published online: 21 October 2008

(c) The Author(s) 2008. This article is published with open access at Springerlink.com

The first three papers in this issue deal with the physicianpatient-relationship. Helge Skirbekk focuses on the microethical issue of trust in the physician-patient-relationship. In most of the medical encounters trust is taken for granted as an implicit phenomenon. Patients often simply assume that they can trust their physician. But the physicianpatient-relationship can be made a topic for negotiations if either party finds reason for it. Examples are non-compliance of the patient and doctors who drink too much. Negotiating trust is something one cannot always avoid in order to build an adequate physician-patient-relationship. Andreas Langer et al. focus on the physician-patient-relationship from a somewhat unusual perspective. They attempt to build a bridge between economic theory and medical ethics by applying elements of new institutional economics to ethically relevant dimensions of the physician-patient-relationship. Physicians cannot always give the best possible treatment for their patients because of financial restrictions. Andreas Langer et al. present a new version of the principal-agent-theory in order to analyse this dilemma of medical doctors. Their model of the so-called dual principal-agent relationship can be used to widen the perspective of medical ethics. Individual ethics of the physician-patient-relationship should be complemented with institutional, especially economic, considerations. In their paper, Kjetil Rommetveit and Rouven Porz tell the story of a patient facing the tough decision of whether to be tested for Huntington's disease or not. They interpret this story from two different philosophical points of view: Aristotle's perception of Greek tragedy and Karl Jaspers'

W. Dekkers $(\bowtie) \cdot$ B. Gordijn

UMC St Radboud Nijmegen, P.O. Box 9101, Nijmegen,

The Netherland

e-mail: v.hulsman@iq.umcn.nl notion of boundary situations (Grenzsituationen). The authors argue that philosophical-anthropological positions like these two may be useful for elucidating ethical dilemmas in the clinical setting and for gaining a deeper understanding of these dilemmas. They can be seen as hermeneutic tools for situating clinical dilemmas in a broader cultural and philosophical perspective.

The next three papers can be subsumed under the heading of research ethics in a pluralistic society. Lars Øystein Ursin tackles the problem of informed consent in biomedical research. Taking consent for biobank research as an example, he argues that in ethical considerations there is often a confusion of autonomy with liberty interpreted as freedom of choice. In his view we need to make a clear distinction between two ways of understanding the notion of personal autonomy, that is, a proceduralist conception linking autonomy with authenticity and a substantivist conception linking autonomy with control. Informed consent requirements in medical research may bring about a conflict between a participant's interest in personal autonomy with his or her interest in liberty. Ilhan Ilkilic and Norbert Paul also focus on biomedical research, especially on genome diversity research. An important part of genome diversity research is taking blood and tissue samples from indigenous populations. The authors widen the scope from micro issues such as informed consent and autonomy of probands to a wider approach in which also cultural-philosophical, meta-ethical, and phenomenological aspects are taken into account. They show a few limits of current guidelines used in international genome diversity studies and end up with some conclusions to further develop these international guidelines. From this paper it is not a big step to the following one. Chris Durante's paper does not deal with clinical medicine or biomedical research, but with bioethics in a pluralistic society. In his view, many theorists fail to take into consideration the 
pertinence of religious pluralism, cultural differences, and the moral diversity that pervades society. His paper offers a critical analysis of a number of leading methods of addressing pluralism in bioethics. In particular, it discusses the relationship between religious pluralism and particularism in relation to bioethical methodology. Durante presents the foundations of a new conceptual framework for bioethical methodology which takes seriously the moral diversity of our modern society.

The next three papers relate to the philosophy of psychiatry, psychoanalysis and psychotherapy. Tim Thornton, Ajit Sjah and Philip Thomas deal with the problem of psychiatric diagnosis. Starting point is the view that psychiatric diagnosis is not only based on individual experiences and accounts of patients, but also on 'testimony', that is a transmission of knowledge through the reports of others. This means that a purely 'internal' account of knowledge (individualism or internalism) cannot account for the important role of testimony in psychiatric diagnosis. The authors outline one externalist model and draw some consequences for the practice of psychiatry. Gerben Meynen and Jacco Verburgt tackle the problem of Wilhelm Dilthey's distinction between causal explanation and hermeneutic understanding. They critically analyse Heidegger's Zollikon Seminars in which Heidegger takes a rather critical stance towards psychoanalysis because of its causal and objectifying approach of the human being. In the authors' view, Heidegger has overlooked the peculiar nature and complexity of psychotherapy and psychiatry, namely that these medical disciplines combine a hermeneutical with a natural science approach not only on a theoretical, but also on a practical level. The authors argue that causal explanation and hermeneutic understanding are not mutually exclusive approaches. Stephen Wilmot deals with the practice of psychotherapy, especially in the UK. The problem is that 'psychotherapy' is an umbrella term which covers many different forms of therapy ranging from cognitive behavioural therapy to psychoanalysis. Another problem is that the resources available for psychotherapy are not equally divided among the various methods. Using Rawls' theory of justice the author tackles the question what would be a fair way of distributing resources between psychotherapies within the UK's health care system.

Finally, this issue contains two papers which could not be categorized under one of the themes just mentioned. Dean Rickles' paper deals with an age old philosophical problem, which recently attracted also the attention of several authors in Medicine Health Care and Philosophy: causality, causal inference and causal explanations. Taking complex intervention research as an example and based upon an analysis of randomized trials and observational studies, Rickles argues that we need to reframe the way in which we think about causal inference in complex intervention research. In his paper, Teun Dekker focuses on the common liberal justification of 'perfectionist enhancement', that is, the practice of designing children who are born with certain genetic traits. He critically analyses the common held idea that liberalism, which has a reputation for being permissive of all kinds of practices, grants parents the right to do so. He argues that liberals should be wary of such practices. The practice of 'perfectionist enhancement' cannot be justified in neutral terms as liberalism presupposes, and liberals should be skeptical of it.

Open Access This article is distributed under the terms of the Creative Commons Attribution Noncommercial License which permits any noncommercial use, distribution, and reproduction in any medium, provided the original author(s) and source are credited. 